\title{
Erratum to: Failed pneumoperitoneum for laparoscopic surgery following autologous Deep Inferior Epigastric Perforator (DIEP) flap breast reconstruction: a case report
}

\author{
Daniel M. Balkin ${ }^{1}$, Quan-Yang Duh², Gabriel M. Kind ${ }^{3}$, David S. Chang ${ }^{3}$ and Mary H McGrath ${ }^{\text {1* }}$
}

\section{Erratum}

Following publication of the original article in $B M C$ Surgery [1], it was brought to our attention that the numbering of Figs. 1 and 3 was switched during the production phase of manuscript publication, and is therefore incorrect.

The correct numbering of the figures should be the following:

- Figure 1. Illustrations of Various Operative Stages of Patient's Breast Reconstruction.

- Figure 2. Patient Photographs Pre and Post Breast Cancer Surgery and Reconstruction.

- Figure 3. Computed Tomographic Imaging Prior to Laparoscopy Following Breast Surgery.

Please find below the figures with the correct numbering. The original article has been updated with the changes. We apologize for the inconvenience this may have caused.

\begin{abstract}
Author details
${ }^{1}$ Department of Surgery, Division of Plastic and Reconstructive Surgery, University of California San Francisco, San Francisco, CA, USA. ${ }^{2}$ Department of Surgery, Section of Endocrine Surgery, University of California San Francisco, San Francisco, CA, USA. ${ }^{3}$ Department of Plastic Surgery, California-Pacific Medical Center, San Francisco, CA, USA.
\end{abstract}

Published online: 13 July 2016

\section{Reference}

1. Balkin DM et al. Failed pneumoperitoneum for laparoscopic surgery following autologous Deep Inferior Epigastric Perforator (DIEP) flap breast reconstruction: a case report. BMC Surg. 2016;16:28.
Received: 10 May 2016 Accepted: 24 May 2016

\footnotetext{
Submit your next manuscript to BioMed Central and we will help you at every step:

- We accept pre-submission inquiries

- Our selector tool helps you to find the most relevant journal

- We provide round the clock customer support

- Convenient online submission

- Thorough peer review

- Inclusion in PubMed and all major indexing services

- Maximum visibility for your research
}

\footnotetext{
* Correspondence: mary.mcgrath@ucsf.edu

1 Department of Surgery, Division of Plastic and Reconstructive Surgery,

University of California San Francisco, San Francisco, CA, USA

Full list of author information is available at the end of the article

Submit your manuscript at www.biomedcentral.com/submit 

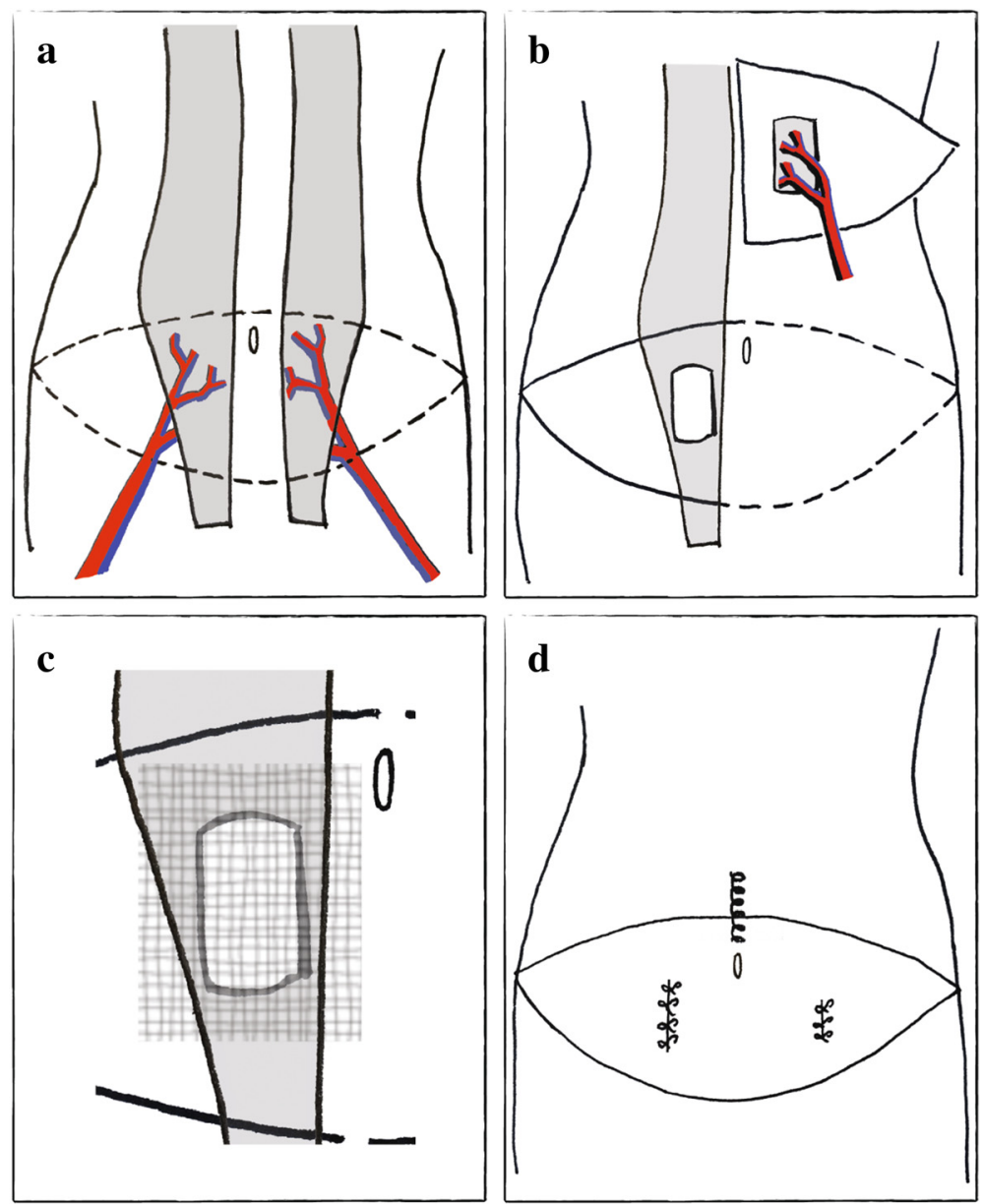

Fig. 1 Illustrations of Various Operative Stages of Patient's Breast Reconstruction. a Abdominal wall depicting bilateral rectus abdominis muscles (grey) with associated deep inferior epigastric arteries (red) and veins (blue). Dashed line indicates skin and soft tissue flaps harvested for breast reconstruction; b Right-sided DIEP flap used to recreate the left breast mound superimposed over left chest wall. Flap includes a portion of the right rectus abdominis muscle (grey) and rectus fascia to surround and protect the perforating vessels; c Small defect in right rectus abdominis muscle and fascia with a mesh underlay repair (hatched area reflects SeriScaffold ${ }^{\circledR}$ mesh); d Areas of rectus abdominis fascial plication 

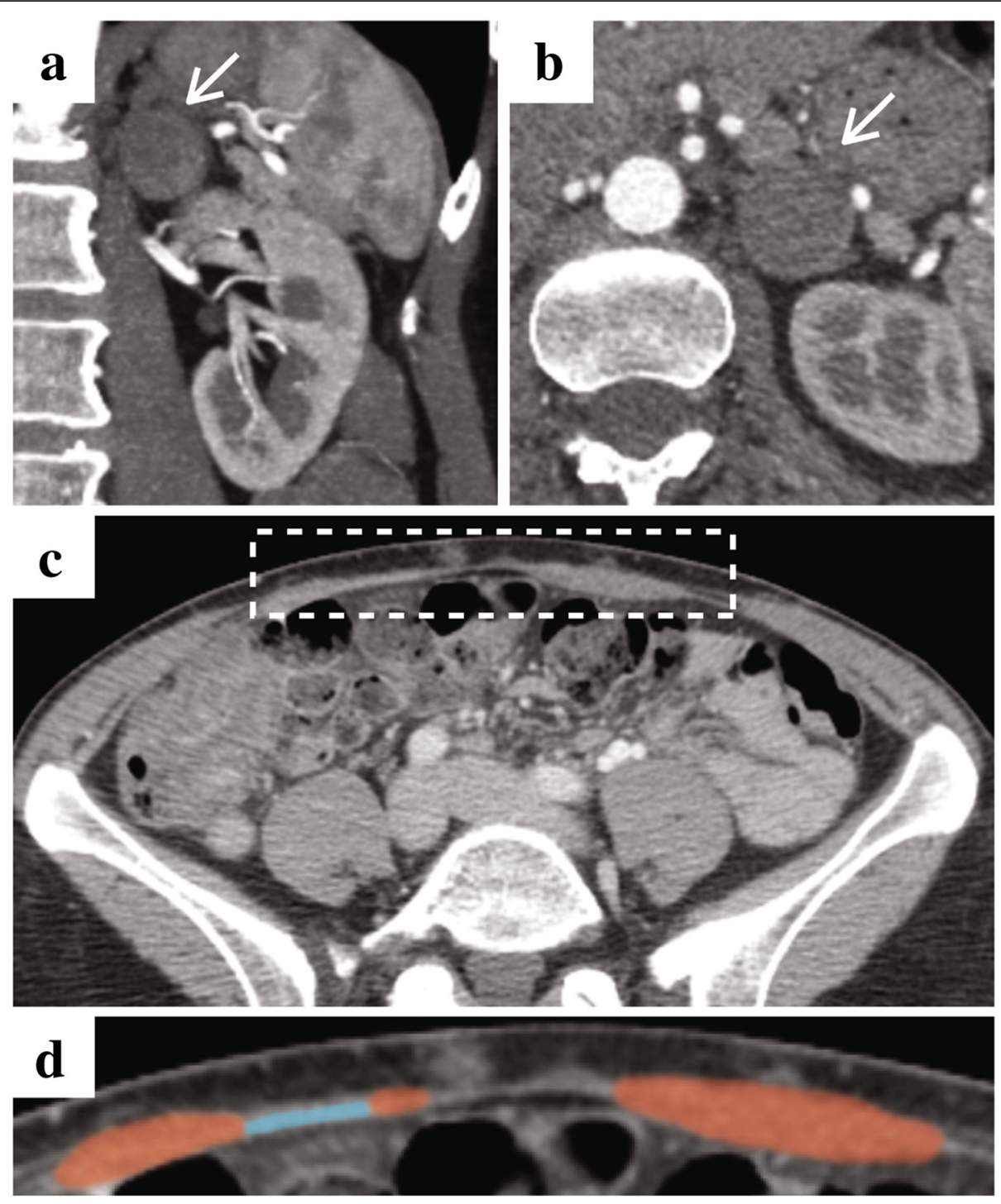

Fig. 3 Computed Tomographic Imaging Prior to Laparoscopy Following Breast Surgery. a Coronal and $\mathbf{b}$ axial images demonstration left-sided pheochromocytoma. c Low-magnification axial image of the abdomen (white box highlights anterior abdominal wall). d High-magnification axial image of the anterior abdominal wall (red and blue indicate rectus abdominis muscle and mesh, respectively) 